Dafs diese Vorstellungsweje von der Zusammensetzung des chemisch reinen Stearins die richtige ist, dafür sprechen die Bestimmungen der bei der Verseifung des freilich noch nicht ganz reinen Stearins entstehenden Stearinsäuremenge, welche $\mathrm{Cheuvreul}{ }^{2}$ ) und $\mathrm{P} . \mathrm{Duff} \mathrm{y}^{2}$ ) ausgeführt haben. Ersterer erhielt 94,9, 94,65, 94,40, 94,6, 95, I Proc. Stearinsäure. Sein Stearin war noch mit ziemlich viel Palmitin veruureinigt, mufste also etwas zu wenig der fetten Säure liefern. Duffy, der mit nahezu reinem Steariu operirte, fand 95,76, 95,51, 95,50, 95,59 Pro. cent Stearinsäure.

Auch ich habe früher die aus verschicdenen Proben noch unreinen Stearins erhaltene Stearinsäuremenge bestimint, und verschiedene Zahlen gefunden, je nach der Reinheit desselben. Verschiedene Proben des aus Menschenfett erhaltenen lieferten 94,3, 94,8, 93,5 Proc. Stearinsäure. Hier war offenbar Palmitin in reichlicher Menge vorhanden. Aus dem aus Hammeltalg dargestellten erhielt ich dagegen 95,60 und 95,65 Proc. Stearinsäure.

Die Formel für das Stearin ist

$$
\left.2\left(\mathrm{C}^{36} \mathrm{H}^{35} \mathrm{U}^{3}+\mathrm{HO}\right)+\mathrm{C}^{36} \mathrm{H}^{35} \mathrm{O}^{3}+\mathrm{C}^{6} \mathrm{H}^{3} \mathrm{O}\right) \text {. }
$$

\title{
IX. Ueber die Wirkung der Salpetersäure auf
} Stearinsäure; oon W. Heintz.

Seit 14 Jahren wird von den Chemikern allgemein angenomınen, dafs die Stearinsäure durch Einwirkung von Salpetersäure oder einer Mischung von chromsaurem Kali und etwas verdünnter Schwefelsäure also durch oxydireude Mit-

1) Recherches s. l. corps gras d'urigine animale p. Che "reul, Paris 1823, p. 262."

2) The quarlerly journal of the chemicul society of Lonilon, Vol. $V$, p. 305. * 
tel in Margarinsïure äbergefülnt werde. Vamentlich Bro. ine is ') und Redten bacher ${ }^{2}$ ) haben Versuche angestellt. durch welche jene Aumahue beyründet zu werden scheint. Sie sind die einzigen, anf welche sie sich stïtzt. Erstere fand nämlich, dafs reinc Stearinsiure, wenn man sie eine halbe Stunde lang in der Siedhitze mit concentrirter Salpetersäure behandelt, sich in ganz reine Margarinsïure verwandelt. Diefs ist jedoch das einzige, was er über diese Reaction anführt. Man kann daher nicht beurtheilen, ob scine Auwabe richtig ist, da man dic Gründe nicht kennt, wclche ihn veraulafst haben, das l'roduct jener Einwirkung für reine Margarinsäure zu halten.

Redtenbacher giebt fast eben so kurz an, dafs wemn Talgsiaure (so scheinen Redtenbacher und Bromeis die in den Stearinsiiurefabriken aus Ochsentalg gewonnene unreine Säure zu nennen) mit ciner Mischung vou Schwefelsäure, Chromsäure und etwas Wasser crwärmt wird, die Mischung sich grün firbe von gebildeteu Chromoxyd und dafs ein Theil der Stenrinsïure in Margarinsiumb übergegangen sey. Jiefs schliefst er allein aus dem Umstande, dafs, wenu man die erhaltene bei $64^{\circ}$ bis $65^{\circ} \mathrm{C}$. schmelzende Siure aus Alkohol krystallisirt, die Stearinsäure zuerst auschiefst und aus der Lüsung in Alkohol ciuc Süurc erhalten werden kann, die bei 59 bis $60^{\circ}$ C. schmilzt. Die bei dieser Temperatur schmelzende Säure kann aber recht wohl ein Gemisch zweier oder inehrerer Säuren gewesen seyn.

Diese vermeintliche Thatsache, dal's durch einfache Oxydation aus Stearinsäure Vargarinsäure cntstehe, benutate man, un namentlich die Vorstellung fest zu begrüuden, dafs die Mlargarinsäure dasselbe organische Radical cuthielte, als die Stcarinsäure und dals in dieser zwei Atome desselben mit 5 Atomen Sanerstoff in jener 1 Atom mit 3 Atomen Saucrstoff verbunden seyen. Mit dieser Vorstel-

1) Irun. der Clacm. und Pharm. Bd. 35, S. 89. *

2) Anu. der Clucm. und Pharm Bal. 35, S. G5* 
lung war die leichte Ueberführbarkeit jener Säure in dieṣe durch oxydirende Mittel vollkoimmen in Einklang.

Durch meine Uintersuchung der Stcariusiiure und ihrer neutralen Salze ') habe ich jedoch zunäclist dargethan, dafs die Stearinsäure nicbt dasselbe Radical cuthiilt, wie die Margarinsäure. Die Zusammeusetzuug beider Säuren erlaubt nun nirlth mehr die leichte Umwandlung der einen in die andere durch oxydirende Mittel durch eine einfache Sauerstoffaufnahme, zu erklïren; Kohlenstoff und Wasserstoff müfsten dabei in Kohlenstiure und Wasser übergeführt werden. Doch hat man bei jener Reaction bis jetzt keine Koblensïure-Entwickelung benerkt.

Die von Bromeis und Redtcubacher bchauptete Thatsache wurde noch inehr zweifelhaft, als ich fand, dafs in den Verseifungsproducten der Fette gar keine Säure enthalten ist, welche in ilirer Zusammensetzutig der Margarinsäure entspricht. Daraus folgt freilich nicht umittelbar, dafs durch Einwirkung oxydirender Mittel auf Stearinsäure ebenfalls nicht Margarinsäure entstehen könne, es war dadurch aber allerdings löchst unwahrscheinlich geworden.

Um mich selbst davon zu überzeugen, welcher Art dic Veränderung ist, welche die Stearinsäure durch Einwirkung der Salpetersäure erleidet, übergofs ich einen Theil jener Säure in chemisch reinen Zustande mit dem 1 ijfarhen Ge. wicht gewöhulicher Salpetersäure und kochte die Mischung 12 Minuten lang. Der anfänglich etwas über $69^{\circ} \mathrm{C}$. licgende Schmelzpunkt sank dadurch auf $67^{\circ}, 5 \mathrm{C}$. Beim Erkalten crstarrte die Säure schuppig krystallinisch ganz wic reine Stearinsüure. Die Mischung wurde unter Zusatz von etwas stärkerer Salpetersäure nochmals 10 Minuten gekocht. Dic auf der Obcrfläche schwimmende Säure wurde bei $63^{\circ}, 3 \mathrm{C}$. flüssig. Sie erstarrte nicht mehr recht deutlich schuppig. Die wellige Oberlliche erschien riel mehr undeutlich fein nadelig. Als die Säure noch 20 Minuten gckocht wurde, sank der Schmelzpunkt nur unbedeutend, 1) Paggend. Ann. Bd. 87, S. 558 bis $568^{*}$. 
auf $62^{\circ}, 7$ C. Auch die äufseren Eigenscbaften dieser Siiure waren der bei $63^{\circ}, 3 \mathrm{C}$. schmelzenden ganz ähnlich. Ich kochte deshalb die Săure unter Zusatz von starker Salpetersäure noch eine volle Stunde. Dadurch sank der Schmelzpunkt auf $59^{\circ}, 8 \mathrm{C}$. Die Säure war nun zwar krystallinisch aber wenig deutlich, erschien auch nicht nadelig krystallisirt, wie die vermeintliche Margarinsänre, deren Schmclzpunkt sie allerdings besafs. Sie war weich, und roch stark nach Buttersäure oder anderen ähnlichen flüchtigen Säuren der Reihe der fetten Säuren. Daher konute ich die Süırc nicht für rein halten, hoffte aber sie durch Umkrystallisation aus Alkohol leicht von diesen riechenden Säuren trennen zu können. Nach einmaligem Umkrystallisiren sticg der Schmelzpunkt auf $68^{\circ}, 7 \mathrm{C}$., welcher nahezu der der reinen Steariusäure ist. Aus Alkohol krystallisirte sie in schönen grofsen Blättern, wie die reine Stearinsäure. In der That war diese Säure in Wesentlichen Stearinsäure, von der sie sich durchaus nicht unterschied. Die durch Eiuwirkuog der Salpetersäure auf die Stearinsäure erhaltene in der salpetersauren Flüssigkeit nicht lösliche fette Masse besteht also zumeist aus Stearinsäure, der nur leicht iı. Alkohol lösliche flüchtige Säuren der Fettsäurereihe beigemischt sind.

Da ich bei Anwendung einer uicht ganz concentrirten Salpetersäure die Mischung dieser Säure mit der Salpetersäure länger als $1 \frac{1}{2}$ Stunden hatte kochen müssen, bis der Schmelzpunkt der Săure auf den der vermeintlichen Margarinsäure herahgesunken war, wäbrend B romeis angicbt, dafs schon nach einer halben Stunde die Stearinsäure in Margarinsäure umgewandelt sey, weudete ich bei einem zweiten Versuche die stärbste Salpetersäure als Oxydationsmittel an. Indessen mufste ich auch in diesem Falle $1 \frac{1}{2}$ Stunde kochen, un nur eine kleine Menge reiner Stearinsäure so weit zu verändern, dafs ihr Schmelzpunkt bei $59^{\circ} \mathrm{C}$. lag. Auch diese Säure roch nach flüchtigen Säuren der Fettsäurereihe. Sie wurde in Alkohol gelöst, aus deın sie sich beim Erkalten in grofsen schönen Blättern abschied. 
Sie wurde abgeprefst und der Schmelzpunkt bestimnt, welcher genau bei $69^{\circ} \mathrm{C}$. Iag. Also auch die in diesem Falle gewonnene Säure war Stearinsäure, die nur durch kleinc Mengen flüchtiger Säureu verunreinigt war. Wäre Palmitinsäure oder irgend eine andere in Alkohol schwerer lös. liche fette Säure zugegen gewesen, so würde der Schmelzpunkt nicht durch einmaliges Umkrystallisiren auf den der Stearinsäure erhoben worden seyn, und die sich aus Alkohol abscheidende Säure würde nicht in so schönen Blättern krystallisirt seyn, wie diefs der Fall war.

Auch war aus der von der ausgeschiedenen Steariusäure abgeprefsten alkoholiscben Flüssigkeit keine Säure zu erhalten, die für Margarinsäure bätte gehalten werden können. Als dieselbe mit kochendem $W$ asser gemischt wurde, schied sich eine Säure aus, die bei einigen und 40 Graden schmolz, nach flüchtigen Säuren roch, und, als sic in wenig Alkohol noch einual gelöst wurde, bein Erkalten einen zweiten Anschufs von fast reiner Stearinsäure lieferte. Die erhaltene Säure schıolz bei $68^{\circ}, 5 \mathrm{C}$.

Durch diese Versuche ist es also erwiesen, dafs auch durch Einwirkung vou kochender Salpetersäure auf Stearinsäure keine mit den Eigeuschaften der vermeintlichen Margariusäure begabte Säure eutsteht. Es ist wohl kaum zu bezweifeln, dals auch bei Einwirkung der Mischung von Chromsäure und Schwefelsäure dic Zersetzungsproducte ganz äbnlicher Natur sind. So viel ist aber gewifs, dafs der Versuch von Redtenbacher, welcher durch Einwirkung jener Reagentien ein bei $64^{\circ}$ bis $65^{\circ} \mathrm{C}$. schmelzendes Geınisch rou Stearinsäure und Margarinsäure erhalten habeu will, für die Entstehung dieser Säure aus der Stearinsäure durch oxydirende Mittel nicbt als Beweis dienen kann. Denn Red ten b acher schlofs auf die Gegenwart der Margarinsäure allein daraus, dafs, als die erbaltene Säure in Alkohol gelöst und die beim Erkalten sich abscheidende Stearinsïure abgeprefst worden war, aus der alkoholischen Lösung eine Säure abgeschieden werden kounte (auf welche Weise wird nicht angegeben), deren Schmelzpunkt bei $59^{\circ}$ 
bis 60" C. lag. Jetzt wissen wir, dals die Steariusüure mit den meisten fetten Süu:en wenigstens ein bei dieser Tem. peratur schmelzendes Gemisch bilden kann.

X. Nachträgliche Notiz zu meiner Methodle der Scheidung des Eisenoxyds corn Eiscnoxydul: con Th. Scheerer.

Die in Bd. 86, S. 91 dieser Anmalen beschriebene Ml:thode der Scheidung des Eisenoxyds vom Eisenoxydul besteht hauptsäcblich darin, dafs man die betreffende Veibindung, in einer Atmosphäre von Kolılensäure, durch Schwefelsaiture zersetzt oder wenigstens dadurch ihren E:sengehalt extrahirt, dicse Solution mittelst hohlensanrer Anmoniaklösung verdünnt ohue sic damit zu sättigen oder übersättigen, und darauf - unter Erhitzen der Flüssigkeit zum Kochen - das Eisenoxyd durch wasserf́reie neutrale kohlensaure Magnesia (gepulverten Magnesit) ausfällt. Diese Scheidungsart war von mir, meinem Assistenten Hrn. Rob. 'Richter und Hrn. I)r. Walmstedt frï. her ausschliefslich nur bei solchen Vérbindungen geprüf und in Anwendung gebracht worden, welche sich entwe. der schon durch verdünnte Schwefelsäure, oder doch bei einer unter $326^{\prime \prime} \mathrm{C}$. liegenden Temperatur zersetzen lic. fsell. Dafs dicselbe auch bci Verbindungen anirendbar. sey, deren erforderliche Aufschliefsung crst durch anhaltendes Kochen mit concentrirter Schwefelsüure erfolgt, hiclt ich anfangs für möglich, obgleich. dieser Annahme die bekannte Erfahrung entgegenstand: dafs Eisenoxydul und Eisenoxydoxydul, mit concentrirter Schwefelsiiure gekocht, sich unter Entwicklung von schwefliger Säure allmälig iı Eisenoxyd unwandeln. Ich überzengte mich aber spïter - 